\title{
Real-world results of the implementation of preoperative anaemia clinic with intravenous iron therapy for treating iron-deficiency anaemia: a propensity-matched case-control study
}

\author{
Hairil R. Abdullah ${ }^{1}$, Tanakorn Thamnachit ${ }^{1}$, Ying $\mathrm{Hao}^{2}$, Wan Yen Lim $^{1}$, Li Ming Teo ${ }^{1}$, Yilin Eileen Sim ${ }^{1}$ \\ ${ }^{1}$ Department of Anaesthesiology, Singapore General Hospital, 169608, Singapore; ${ }^{2}$ Health Services Research Centre (HSRC), Singapore Health \\ Services, 169608, Singapore \\ Contributions: (I) Conception and design: HR Abdullah, T Thamnachit, WY Lim, YE Sim, LM Teo; (II) Administrative support: All authors; (III) \\ Provision of study materials or patients: All authors; (IV) Collection and assembly of data: HR Abdullah, T Thamnachit, WY Lim, YE Sim, LM Teo; \\ (V) Data analysis and interpretation: All authors; (VI) Manuscript writing: All authors; (VII) Final approval of manuscript: All authors. \\ Correspondence to: Yilin Eileen Sim. Consultant, Department of Anaesthesiology, Singapore General Hospital, 169608, Singapore. \\ Email: Eileen.sim.y.1@singhealth.com.sg.
}

Background: Preoperative anaemia is associated with blood transfusion and longer hospital length of stay. Preoperative iron deficiency anaemia (IDA) can be treated with oral or intravenous (IV) iron. IV iron can raise haemoglobin faster compared with oral iron. However, its ability to reduce blood transfusion and length of stay in clinical trials is inconclusive. This study aims to compare blood transfusion and hospital length of stay between anemic patients who received preoperative IV iron versus standard care, after implementation of a protocol in 2017 to screen patients for preoperative IDA, and its treatment with IV iron.

Methods: Retrospective before-after cohort study comparing 89 patients who received IV iron preoperatively in 2017, with historic patients who received oral iron therapy (selected by propensity score matching (PSM) from historic cohort of 7,542 patients who underwent surgery in 2016). Propensity score was calculated using ASA status, age, gender, surgical discipline, surgical risk and preoperative haemoglobin concentration. Both 1:1 and 1:2 matching were performed as sensitivity analysis.

Results: After PSM, there was no statistically significant difference in distribution of preoperative clinical variables. There was no significant difference in proportion of cases requiring transfusion nor a difference in average units transfused per patient. IV iron cohort stayed in hospital on average 8.0 days compared to nonIV iron cohort $14.1-15.1$ days $(\mathrm{P}=0.006, \mathrm{P}=0.013$ respectively). Average time from $\mathrm{IV}$ iron therapy to surgery was 10.5 days.

Conclusions: Preoperative IV iron therapy for patients with IDA undergoing elective surgery may not reduce perioperative blood transfusion, but this could be due to the short time between therapy and surgery. Implementation of IV iron therapy may reduce hospital length of stay compared to standard care for anemic patients, although this may be enhanced by concomitant improvement in perioperative care.

Keywords: Anaemia; intravenous iron; perioperative blood transfusion; hospital length of stay; surgery

Submitted Jun 25, 2020. Accepted for publication Sep 30, 2020.

doi: 10.21037/atm-20-4942

View this article at: http://dx.doi.org/10.21037/atm-20-4942 


\section{Introduction}

Preoperative anaemia is commonly detected prior to surgical procedures worldwide, with prevalence ranging from $25 \%$ to $60 \%$ (1-7). Preoperative anaemia is associated with poor postoperative outcomes such as an increased risk for perioperative blood transfusion, prolonged hospital stay $(8,9)$ and increased rates of adverse cardiac and noncardiac complications, including wound infections and sepsis $(1,2,8-16)$. Most importantly, preoperative anaemia is the strongest predictor of perioperative allogeneic blood transfusion (ABT). While perioperative blood transfusion is usually given to avoid the detrimental effects of acute anaemia by producing a quick and effective increase in haemoglobin concentrations, there are several important drawbacks to this approach. Blood transfusion exposes patients to risks of a transfusion reaction and infection, and has been associated with poor patient outcomes (e.g., higher mortality and morbidity rates) in studies comparing cohorts of transfused patients with non-transfused (or lesstransfused) patients across various patient populations and clinical settings $(11,15,17-22)$. Apart from the health risks of blood transfusion, there are also financial costs to the patient, as well as the health system for handling, testing and administering blood (23). Hence, strategies to reduce blood transfusions are prudent and are of great public health importance.

The most frequent underlying reason for preoperative anaemia is iron deficiency $(24,25)$. In one large multicenter study of non-cardiac surgical patients $(\mathrm{N}=2,115$; $48 \%$ women), iron deficiency was evident in $75 \%$ of the patients (26). Iron deficiency anaemia (IDA) can be treated with iron supplementation via oral or intravenous (IV) route, and both forms have been shown to improve haemoglobin concentrations preoperatively $(24,27)$. Oral iron is poorly absorbed when administered together with other drugs such as proton pump inhibitors or in the presence of chronic inflammation and gastrointestinal diseases $(28,29)$. Furthermore, frequent side effects such as abdominal pain, constipation, and heartburn contribute to poor adherence $(30,31)$. Intravenous (IV) iron circumvents the problems associated with oral iron. It is more effective in replenishing iron stores and in increasing haemoglobin concentrations (32-34).

Correspondingly, there has been an increasing call for the incorporation of preoperative IV iron treatment in the assessment pathway for elective surgical patients (24). Despite the efficacy of preoperative IV iron in increasing haemoglobin concentrations, to date, there is mixed evidence to support its ability to reduce blood transfusion requirements and length of stay in clinical trials $(27,35,36)$. Furthermore, trials are conducted in pre-defined spectrum of patients undergoing specific types of surgery, and do not reflect the breadth of surgical patient population in a tertiary hospital. There is a paucity of studies examining the efficacy of IV iron therapy when implemented within real world conditions. Thus, the aim of this study is to compare the incidence of blood transfusion and hospital length of stay between anemic patients who received IV iron prior to undergoing elective surgery versus standard care, after the implementation of a protocol for screening of irondeficiency and treatment with IV iron in a preoperative clinic within a tertiary hospital. We present the following article in accordance with the STROBE reporting checklist (available at http://dx.doi.org/10.21037/atm-20-4942).

\section{Methods}

This is a retrospective before-after cohort study of patients who received IV iron preoperatively, propensitymatched to patients who received standard care as controls. Institutional Review Board approval was obtained (SingHealth CRB 2014/651/D) prior to starting the study. Due to the retrospective nature of the study, no informed consent was required. The study was conducted in accordance with the Declaration of Helsinki (as revised in 2013) and the Harmonized Tripartite Guideline for Good Clinical Practice from the International Conference on Harmonization.

\section{Establishment of preoperative iron-deficiency anaemia screening and treatment}

Patients presenting to the Singapore General Hospital Preoperative Assessment Centre (PAC) for anaesthesia assessment before elective surgery, and who are diagnosed with anaemia (serum haemoglobin $<13 \mathrm{~g} / \mathrm{dL}$ ), would be screened for iron deficiency, which is defined as transferrin saturation $<20 \%$ and serum ferritin $<100 \mathrm{mcg} / \mathrm{L}(24,37)$. This non-gender based definition for preoperative anaemia has been established and used in recent literatures $(24,38)$. Since January 2017, patients diagnosed with IDA would be prescribed either oral or IV ferric carboxymaltose (FCM), according to our institutional protocol (Figures S1,S2). For patients who were given IV FCM, they were given a dose of $15 \mathrm{mg} / \mathrm{kg}$, up to $1,000 \mathrm{mg}$, as an infusion over $15 \mathrm{~min}$ in 


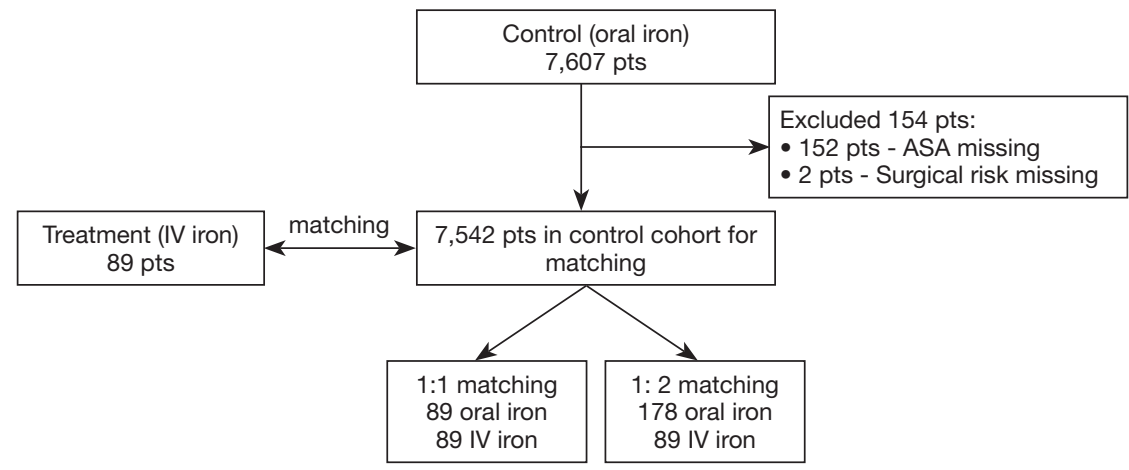

Figure 1 Flowchart of the derivation of the patient cohort. ASA, American Society of Anaesthesiologist physical status score; IV, intravenous.

the outpatient setting. Prior to 2017, IV FCM therapy was not available preoperatively in the outpatient setting, and patients diagnosed with IDA in PAC would only be given oral iron supplement.

\section{Conduct of retrospective chart review}

Our inclusion criteria for the IV FCM (intervention) group are patients who attended the PAC from August 2017 to August 2018 for elective surgeries requiring general anaesthesia or regional anaesthesia, except for transplant, burns and cardiac surgery, and who were diagnosed with iron-deficiency anemia and were prescribed preoperative IV iron therapy. Based on these criteria, we included 94 cases. Data from each patient were retrospectively collected by medical case record review and include: age, gender, American Society of Anaesthesiologist (ASA) status, presence of comorbidities such as ischemic heart disease (IHD) and congestive heart failure (CHF); preoperative drugs such as antiplatelet or anticoagulation use; preoperative haemoglobin, surgical discipline, surgical severity $(39,40)$, units of red blood cell (RBC) transfused perioperatively, days between IV iron therapy and surgery for the IV FCM group, and hospital length of stay. 5 patients were excluded from analysis as their surgeries were postponed after they had received IV iron therapy. The remaining 89 were selected for further propensity score matching.

\section{Propensity matching of intervention group with historic controls}

Historic controls were drawn from a database of 7,607 patients who underwent elective non-cardiac, non-transplant, non-burns surgery in 2016 in our institution before the introduction of preoperative IV FCM therapy. A propensity score was calculated using ASA status, age, gender, surgical severity, surgical discipline and preoperative haemoglobin concentration. 154 had missing values in variables which were used for matching, and hence were excluded from further analysis. The remaining 7,542 were used for propensity score matching. Nearest neighbor matching was performed with 1:1 and 1:2 ratio using the Matchit package in $\mathrm{R}$ 3.5.1, R Core Team (2018). Both 1:1 and 1:2 matching were performed as sensitivity analysis. Eighty-nine were chosen from the historic dataset as control in the 1:1 matching, and 178 patients for the 1:2 matching. Figure 1 shows the flowchart of the derivation of the patient cohort.

\section{Sample size calculation}

From previous unpublished data from our institution, our transfusion rate for anemic patients undergoing moderatehigh risk surgeries is about $40 \%$. Thus, based on findings by Froessler et al. (36), where the administration of IV iron in anemic patients undergoing abdominal surgery led to a reduction in incidence of blood transfusion by half $(30 \%$ to $12 \%$ ), we estimated that for the detection of half the incidence of transfusion in the intervention group (20\%) compared to the control group ( $40 \%$ ), with a $80 \%$ power and alpha error rate of 0.05 , the number in each arm would be 81 . Assuming a missing data rate of $10 \%$, we decided upon a final sample size of 89 in each arm.

\section{Statistical analysis}

Preoperative transfusion was defined as transfusion 
occurring up to 30 days prior to surgery. Intraoperative transfusion was defined as transfusion occurring during the surgery. Postoperative transfusion was defined as transfusion occurring after the surgery, until 30 days after surgery. Outcomes such as incidence of transfusion, average units of RBC transfused per patient in each group and per transfused patient were calculated (36).

All data analyses were carried out using IBM SPSS Statistics v21 software (IBM Corp, Armonk, NY). Continuous variables such as age, preoperative haemoglobin, hospital length of stay, average number of units of RBC transfused per patient and per transfused patient are presented as mean and $95 \%$ confidence interval. Comparison between the two groups for these variables was performed using the 2-tailed student $t$-test. Categorical variables such as ASA status, gender, surgical risk, the presence of comorbidities, and incidence of any transfusion are presented as frequency and percentage in each group. Comparison between the two groups for these variables was made using the Pearson chi-square test. $\mathrm{P}$ values less than 0.05 were taken to be statistically significant.

\section{Results}

The IV iron and historic oral iron groups differed only in distribution of ASA status, mean preoperative haemoglobin concentration, surgical risk and preoperative anticoagulant use (Table 1).

After propensity matching, there was no statistically significant difference in the distribution of variables such as ASA status, age, gender, history of IHD/CHF, antiplatelet, mean preoperative haemoglobin and surgical risk and discipline between the two cohorts (Table 2). There were still differences in preoperative anticoagulant use, but most anticoagulants would be stopped appropriately before surgery. The average time from IV iron therapy to surgery was 10.5 days $( \pm 8.0)$.

Patients in the IV iron group had significantly reduced hospital length of stay (Table 3) (8.0 days, \pm 12.5 ) compared to the oral iron group in 1:1 (15.1 days, $\pm 23.6, \mathrm{P}=0.013$ ) or $1: 2$ matching (14.1 days, $\pm 23.3, \mathrm{P}=0.006$ ). However, the proportion requiring transfusion over the entire perioperative period did not differ statistically (oral iron: $41.6 \%$, IV iron: $38.2-41.0 \%$ ). Neither did the mean units of perioperative transfusion differ statistically (oral iron: 0.9 units, \pm 1.5 ; IV iron: 1.4 units, \pm 3.8 to 1.2 units, \pm 3.0 ) (Table 3).

Of note, the proportion who received intraoperative transfusion was significantly higher in oral iron group (37.1-40.4\%) compared to the IV iron group 20.2\% ( $\mathrm{P}=0.02$ and $\mathrm{P}=0.002)$, but the average units of transfused blood per transfused patient was higher in the IV iron group (2.2 units, \pm 1.8$)$ versus oral iron group $(1.0, \pm 0)$ for both propensity matched cohorts.

There were no statistically discernible differences in pattern of preoperative or postoperative transfusion between groups.

\section{Discussion}

\section{Impact on blood transfusion}

In our study, we did not find any statistically significant difference in the incidence of total blood transfusions in anemic patients undergoing major surgery who received preoperative IV iron (41.6\%) versus historic control which received oral iron supplementation (38.2-41.0\%). Our results reflect the 'real world' impact of preoperative IV iron therapy in our institution. Other perioperative clinics in Muenster University Hospital, Germany and in Spain were also unable to demonstrate any significant impact of preoperative IV iron therapy on perioperative blood transfusion $(41,42)$. Nevertheless, within trial settings, some trials were able to show a positive impact $(36,43,44)$, while others a negligible impact on perioperative blood transfusion $(27,45,46)$.

We feel that in our study, the impact of IV iron therapy could be limited by the short duration from therapy to surgery, which was on average 10.5 days. The average rate of rise in haemoglobin after IV iron therapy in literature is about $1 \mathrm{~g}$ in $2-4$ weeks $(27,35,41)$ thus the resultant rise in haemoglobin concentrations after IV iron therapy in our study cohort may have been minor before the surgery. Although we encourage our surgeons to send patients to the preoperative clinic as soon as they are listed for surgery, most cases are scheduled to be reviewed at the preoperative clinic 2-3 weeks prior to surgery due to short waiting times to surgery in our institution. This reduces the time available for screening and treatment of preoperative iron deficiency anaemia. The merits of preoperative haemoglobin optimization needs to be weighed against the tradeoff of potentially longer waiting time to elective surgeries on a case-by-case basis.

We observed a significant reduction in the incidence of intraoperative blood transfusion in the IV iron group, but this was counterbalanced by an increase in average 
Table 1 Demographic characteristics of the IV iron and entire historic cohort

\begin{tabular}{|c|c|c|c|}
\hline Variable & IV iron (N=89) & Oral iron $(\mathrm{N}=7,607)$ & $P$ value \\
\hline \multicolumn{4}{|l|}{ Gender, n (\%) } \\
\hline Female & $68(76.4)$ & $5,483(72.1)$ & \multirow[t]{2}{*}{0.432} \\
\hline Male & $21(23.6)$ & $2,124(27.9)$ & \\
\hline 1 & $9(10.1)$ & $1,261(16.6)$ & \multirow[t]{4}{*}{0.002} \\
\hline 2 & $42(47.2)$ & $4,296(56.5)$ & \\
\hline 3 & $37(41.6)$ & $1,816(23.9)$ & \\
\hline 4 & $1(1.1)$ & $82(1.1)$ & \\
\hline Dental & $1(1.1)$ & $17(0.2)$ & \multirow{10}{*}{ NA } \\
\hline Otorhinolaryngology & $1(1.1)$ & $520(6.8)$ & \\
\hline Gynaecology & $13(14.6)$ & $1,004(13.2)$ & \\
\hline Maxillofacial & $2(2.2)$ & $44(0.6)$ & \\
\hline Neurosurgery & $3(3.4)$ & $126(1.7)$ & \\
\hline Obstetrics & $1(1.1)$ & $156(2.1)$ & \\
\hline Orthopaedics & $11(12.4)$ & $2,144(28.2)$ & \\
\hline Plastic surgery & $0(0)$ & $336(4.4)$ & \\
\hline General surgery & $2(2.2)$ & $279(3.7)$ & \\
\hline Urology & $8(9)$ & $751(9.9)$ & \\
\hline \multicolumn{4}{|l|}{ Surgical risk, n (\%) } \\
\hline Low & $14(15.7)$ & $3,291(43.3)$ & \multirow[t]{3}{*}{$<0.001$} \\
\hline Moderate & $56(62.9)$ & $3,844(50.5)$ & \\
\hline High & 19 (21.3) & $470(6.2)$ & \\
\hline Preoperative hemoglobin, mean (SD) & $9.6(1.1)$ & $11.5(1.2)$ & $<0.001$ \\
\hline \multicolumn{4}{|l|}{ History of ischemic heart disease, $\mathrm{n}(\%)$} \\
\hline No & $82(92.1)$ & $6,483(85.2)$ & \\
\hline Yes & $7(7.9)$ & $736(9.7)$ & \\
\hline
\end{tabular}

Table 1 (continued) 
Table 1 (continued)

\begin{tabular}{lcc}
\hline Variable & IV iron $(\mathrm{N}=89)$ & Oral iron $(\mathrm{N}=7,607)$ \\
\hline History of congestive heart failure, $\mathrm{n}(\%)$ & $86(96.6)$ & $7,028(92.4)$ \\
No & $3(3.4)$ & $188(2.5)$ \\
Yes & & \\
Antiplatelet use, $\mathrm{n}(\%)$ & $79(88.8)$ & $6,722(88.4)$ \\
No & $10(11.2)$ & $885(11.6)$ \\
Yes & & 1 \\
Anticoagulant use, $n(\%)$ & $84(94.4)$ & $7,500(98.6)$ \\
No & $5(5.6)$ & $107(1.4)$ \\
Yes & & 0.009 \\
\hline
\end{tabular}

ASA score, American Society of Anaesthesiologist physical status score; SD, standard deviation.

units of transfused blood per transfused patient. As this was a retrospective study, and it was not in our institution's protocol to re-check our anemic patient's preoperative haemoglobin on the day of surgery, the increase in preoperative haemoglobin is not known. Intraoperative transfusion is based on clinical signs such as haemodynamic instability, amount of operative bleeding observed and point-of-care tests.

Despite the small numbers in our cohort and the retrospective study design which prevents confirmation of our postulations, we feel that our observations support the importance of implementing preoperative screening and treatment of iron deficiency anaemia within a comprehensive Patient Blood Management program. The physiology behind preoperative treatment of anaemia is sound, but its effect may be incremental, and the greatest benefit can be achieved when this is combined with many other interventions that are aligned with the pillars of patient blood management $(47,48)$. For instance, one orthopaedic center was able to achieve a significant reduction in blood transfusion when preoperative IV iron therapy was introduced together with intraoperative measures such as routine tranexamic acid administration, and adoption of a unified transfusion strategy postoperatively (49).

\section{Impact on length of stay (LOS)}

LOS in the control group was higher than in IV iron group by 6-7 days. This is independent of total transfusion, since the average units of transfusion and incidence of transfusion are similar in both groups on both $1: 1$ and 1:2 matching. Our matching was fairly robust, as we matched the IV iron and historic oral iron group based on relevant medical factors such as degree of preoperative anemia, surgery discipline and risk, age, gender, and ASA status, and we achieved similar distribution of preoperative variables after matching. It is likely that other postoperative factors not accounted for in our study, such as incidence of postoperative complications, contributed to the large difference in LOS.

To date, a sizeable number of randomized control trials (RCT) have been conducted to compare the length of hospital stay in patients who receive preoperative IV Iron therapy to a placebo or standard care $(27,36,50)$. The results have not been consistent. In one RCT, patients scheduled to undergo elective major abdominal surgery were randomized to either IV iron or usual care. Patients in the IV iron group had significantly shorter length of stay (7.0 vs. 9.7 days, $\mathrm{P}=0.026$ ) and reduced incidence of blood transfusion ( $31.25 \%$ vs. $12.5 \%)$. Although haemoglobin concentration at point of discharge between the two groups were similar, the IV iron group had higher haemoglobin concentration at 4-week after surgery (36). Similarly, another RCT involving patients undergoing elective joint arthroplasty found that administration of IV iron to patients with iron deficiency anaemia led to shorter length of stay in hospital ( 6 vs. 8 days, $\mathrm{P}=0.04$ ) compared to patients who received oral iron (50). These results contradict a similar RCT involving patients with non-metastatic colorectal adenocarcinoma scheduled for curative surgery and randomized to receive either 
Table 2 Demographic characteristics of the IV iron and oral iron cohort after 1:1 and 1:2 propensity matching

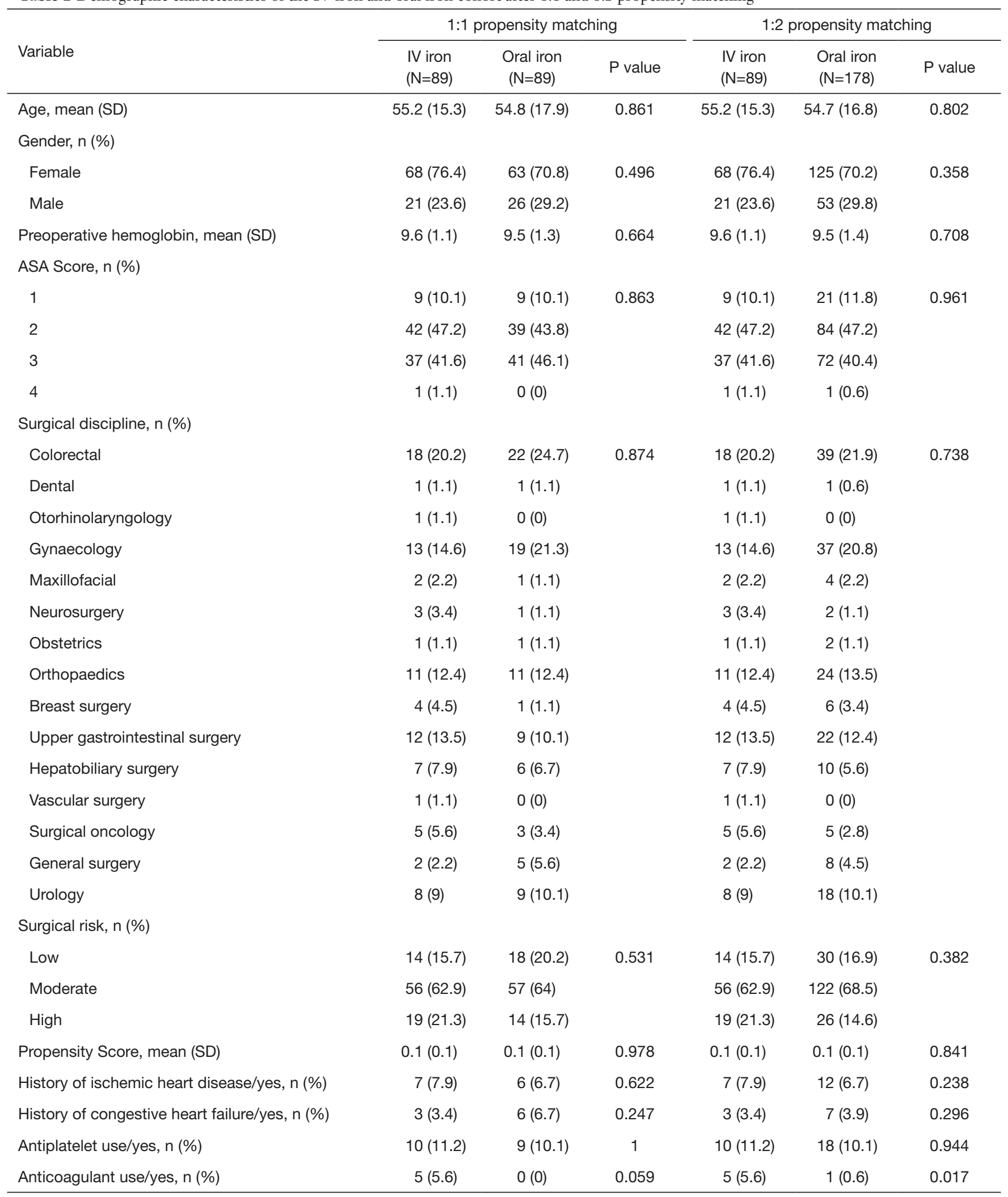

$\mathrm{N}$, number; SD, standard deviation. 
Table 3 Comparison of blood transfusion and hospital length of stay between IV iron and oral iron groups in 1:1 and 1:2 propensity matching

\begin{tabular}{|c|c|c|c|c|c|c|}
\hline Variable & \multicolumn{3}{|c|}{ 1:1 propensity matching } & \multicolumn{3}{|c|}{$1: 2$ propensity matching } \\
\hline Mean units of preoperative transfusion in group (SD) & $0.1(0.4)$ & $0.4(1.5)$ & 0.102 & $0.1(0.4)$ & $0.3(1.2)$ & 0.052 \\
\hline Received Intraoperative transfusion, $\mathrm{n}(\%)$ & $18(20.2)$ & $33(37.1)$ & 0.02 & $18(20.2)$ & $72(40.4)$ & 0.002 \\
\hline Mean units of intra-operative transfusion in group (SD) & $0.4(1.2)$ & $0.4(0.5)$ & 0.567 & $0.4(1.2)$ & $0.4(0.5)$ & 0.734 \\
\hline $\begin{array}{l}\text { Mean units of intra-operative transfusion per transfused } \\
\text { patient (SD) }\end{array}$ & $2.2(1.8)$ & $1(0)$ & 0.01 & $2.2(1.8)$ & $1(0)$ & 0.01 \\
\hline $\begin{array}{l}\text { Mean units of post-operative transfusion per transfused } \\
\text { patient (SD) }\end{array}$ & $1.4(0.8)$ & $3.4(4.5)$ & 0.107 & $1.4(0.8)$ & $2.9(3.6)$ & 0.043 \\
\hline $\begin{array}{l}\text { Received transfusion over entire perioperative period, } \\
\mathrm{n}(\%)\end{array}$ & $37(41.6)$ & $34(38.2)$ & 0.759 & $37(41.6)$ & $73(41)$ & 1 \\
\hline Mean units of peri-operative transfusion in group (SD) & $0.9(1.5)$ & $1.4(3.8)$ & 0.291 & $0.9(1.5)$ & $1.2(3)$ & 0.289 \\
\hline Length of stay, mean (SD) & $8(12.5)$ & $15.1(23.6)$ & 0.013 & $8(12.5)$ & $14.1(23.3)$ & 0.006 \\
\hline
\end{tabular}

$\mathrm{N}$, number; SD, standard deviation.

oral or IV iron. While patients in the IV iron group had higher haemoglobin concentration at the time of surgery, there was no significant difference compared to the oral iron group in terms of length of stay, or units of blood transfusion (27).

Our study adds to a growing literature reporting the realworld impact of screening and treatment of iron deficiency anaemia preoperatively with IV iron therapy. Compared to the reports by other centers, our methodology may be statistically superior, as we utilize propensity-matching to ensure a balance of measured covariates between the two groups (51). In contrast, the study by Ellermann et al. did not attempt to ensure that the preoperative anemic patients who received and did not received IV iron therapy had comparable baseline characteristics (41).

One potential limitation in our study, is that concomitant improvement in perioperative care over time may have also contributed to the reduction in LOS of 6-7 days on average, compared to an average of 2 days in similar RCTs in IV iron $(27,36,50)$. This is an inherent limitation in a pre-post study (52). In addition, as this was a retrospective study, we were also unable to check the haemoglobin concentration on the day of surgery, to assess the response to IV iron therapy.

Preoperative IV iron therapy for iron deficiency anaemia may have the potential to generate significant cost-savings for the hospital, through reducing hospital LOS for patients. Future studies can be done to confirm this finding, and to examine the cost-efficiency of implementing this screening and treatment protocols in the preoperative evaluation clinic. Any change in practice that is proven beneficial needs to be sustainable, and future studies focusing on the implementation of this practice and improving its coverage and sustainability can be conducted (53).

\section{Conclusions}

Our study suggests that preoperative IV iron therapy for patients with iron deficiency anaemia undergoing elective surgery may not have an impact on perioperative blood transfusion, but this could be partially attributed to the short time between preoperative workup and IV iron therapy and surgery, which limits the haemoglobin response. The introduction of IV iron therapy may reduce hospital length 
of stay compared to standard care for anemic patients, when implemented into a preoperative anaemia clinic outside of a trial setting. The beneficial impact of preoperative IV iron therapy may be enhanced if other aspects of patient blood management programs are implemented concurrently.

\section{Acknowledgments}

We would like to thank our research coordinators Ms Brenda Tan Pei Yi and Ms Thin Thiri Naing for their help in data collection. We would also like to thank the support of the Nurse Clinician in our Preoperative Assessment Centre, Ms Ng Kai Lee, for her instrumental help in the implementation of the anaemia screening and treatment pathways.

Funding: This study is funded by department funds from the Department of Anaesthesiology, Singapore General Hospital.

\section{Footnote}

Reporting Checklist: The authors have completed the STROBE reporting checklist. Available at http://dx.doi. org/10.21037/atm-20-4942

Data Sharing Statement: Available at http://dx.doi. org/10.21037/atm-20-4942

Conflicts of Interest: All authors have completed the ICMJE uniform disclosure form (available at http://dx.doi. org/10.21037/atm-20-4942). The authors have no conflicts of interest to declare.

Ethical Statement: The authors are accountable for all aspects of the work in ensuring that questions related to the accuracy or integrity of any part of the work are appropriately investigated and resolved. The study was conducted in accordance with the Declaration of Helsinki (as revised in 2013). The study was approved by Singhealth Central Institutional Review Board of (SingHealth CRB 2014/651/D). Due to the retrospective nature of the study, no informed consent was required to be taken from all the patients.

Open Access Statement: This is an Open Access article distributed in accordance with the Creative Commons Attribution-NonCommercial-NoDerivs 4.0 International License (CC BY-NC-ND 4.0), which permits the non- commercial replication and distribution of the article with the strict proviso that no changes or edits are made and the original work is properly cited (including links to both the formal publication through the relevant DOI and the license). See: https://creativecommons.org/licenses/by-nc-nd/4.0/.

\section{References}

1. Beattie WS, Karkouti K, Wijeysundera DN, et al. Risk Associated with Preoperative Anemia in Noncardiac SurgeryA Single-center Cohort Study. Anesthesiology 2009;110:574-81.

2. Muñoz M, Gómez-Ramírez S, Kozek-Langeneker S, et al. "Fit to fly": overcoming barriers to preoperative haemoglobin optimization in surgical patients. $\mathrm{Br} \mathrm{J}$ Anaesth 2015;115:15-24.

3. Karkouti K, Wijeysundera DN, Beattie WS, Reducing Bleeding in Cardiac Surgery (RBC) Investigators. Risk associated with preoperative anemia in cardiac surgery: a multicenter cohort study. Circulation 2008;117:478-84.

4. Kansagra AJ, Stefan MS. Preoperative Anemia: Evaluation and Treatment. Anesthesiol Clin 2016;34:127-41.

5. Browning RM, Trentino K, Nathan EA, et al, Western Australian Patient Blood Management Program. Preoperative anaemia is common in patients undergoing major gynaecological surgery and is associated with a fivefold increased risk of transfusion. Aust N Z J Obstet Gynaecol 2012;52:455-9.

6. Hamilton W, Lancashire R, Sharp D, et al. The importance of anaemia in diagnosing colorectal cancer: a case-control study using electronic primary care records. Br J Cancer 2008;98:323-7.

7. Spahn DR. Anemia and Patient Blood Management in Hip and Knee Surgery A Systematic Review of the Literature. Anesthesiology 2010;113:482-95.

8. Abdullah HR, Sim YE, Hao Y, et al. Association between preoperative anaemia with length of hospital stay among patients undergoing primary total knee arthroplasty in Singapore: a single-centre retrospective study. BMJ Open 2017;7:e016403.

9. Sim YE, Wee HE, Ang AL, et al. Prevalence of preoperative anemia, abnormal mean corpuscular volume and red cell distribution width among surgical patients in Singapore, and their influence on one year mortality. PLoS One 2017;12:e0182543.

10. Baron DM, Hochrieser H, Posch M, et al. Preoperative anaemia is associated with poor clinical outcome in noncardiac surgery patients. Br J Anaesth 2014;113:416-23. 
11. Wu W-C, Schifftner TL, Henderson WG, et al. Preoperative hematocrit levels and postoperative outcomes in older patients undergoing noncardiac surgery. JAMA 2007;297:2481-8.

12. Hallward G, Balani N, McCorkell S, et al. The Relationship Between Preoperative Hemoglobin Concentration, Use of Hospital Resources, and Outcomes in Cardiac Surgery. J Cardiothorac Vasc Anesth 2016;30:901-8.

13. Miceli A, Romeo F, Glauber M, et al. Preoperative anemia increases mortality and postoperative morbidity after cardiac surgery. J Cardiothorac Surg 2014;9:137.

14. Bydon M, Abt NB, Macki M, et al. Preoperative anemia increases postoperative morbidity in elective cranial neurosurgery. Surg Neurol Int 2014;5:156.

15. Khanna R, Harris DA, McDevitt JL, et al. Impact of Anemia and Transfusion on Readmission and Length of Stay After Spinal Surgery: A Single-center Study of 1187 Operations. Clin Spine Surg 2017;30:E1338-E1342.

16. Gupta PK, Sundaram A, Mactaggart JN, et al. Preoperative anemia is an independent predictor of postoperative mortality and adverse cardiac events in elderly patients undergoing elective vascular operations. Ann Surg 2013;258:1096-102.

17. Shander A, Javidroozi M, Ozawa S, et al. What is really dangerous: anaemia or transfusion? Br J Anaesth 2011;107:i41-59.

18. Whitlock EL, Kim H, Auerbach AD. Harms associated with single unit perioperative transfusion: retrospective population based analysis. BMJ 2015;350:h3037.

19. Ferraris VA, Hochstetler M, Martin JT, et al. Blood transfusion and adverse surgical outcomes: The good and the bad. Surgery 2015;158:608-17.

20. Koch C, Li L, Figueroa P, et al. Transfusion and pulmonary morbidity after cardiac surgery. Ann Thorac Surg 2009;88:1410-8.

21. Seikaly H, Chau J, Harris JR. P220 Transfusion as a Predictor of Recurrence and Survival in Head and Neck Cancer Surgery. Arch Otolaryngol Head Neck Surg 2006;132:908.

22. O'Keeffe SD, Davenport DL, Minion DJ, et al. Blood transfusion is associated with increased morbidity and mortality after lower extremity revascularization. J Vasc Surg 2010;51:616-21, 621.e1-3.

23. Forbes JM, Anderson MD, Anderson GF, et al. Blood transfusion costs: a multicenter study. Transfusion 1991;31:318-23.

24. Muñoz M, Acheson AG, Auerbach M, et al. International consensus statement on the peri-operative management of anaemia and iron deficiency. Anaesthesia 2017;72:233-47.

25. Hong FS, Sieradzki N, Pollock C, et al. Prevalence and causes of preoperative anaemia in elective major surgery patients. Intern Med J 2017;47:1400-4.

26. Muñoz M, Laso-Morales MJ, Gómez-Ramírez S, et al. Pre-operative haemoglobin levels and iron status in a large multicentre cohort of patients undergoing major elective surgery. Anaesthesia 2017;72:826-34.

27. Keeler BD, Simpson JA, Ng O, et al. Randomized clinical trial of preoperative oral versus intravenous iron in anaemic patients with colorectal cancer. Br J Surg 2017;104:214-21.

28. Clevenger B, Richards T. Pre-operative anaemia. Anaesthesia 2015;70 Suppl 1:20-8, e6-8.

29. Weiss G, Goodnough LT. Anemia of Chronic Disease. N Engl J Med 2005;352:1011-23.

30. Tolkien Z, Stecher L, Mander AP, et al. Ferrous sulfate supplementation causes significant gastrointestinal sideeffects in adults: a systematic review and meta-analysis. PLoS One 2015;10:e0117383.

31. Cancelo-Hidalgo MJ, Castelo-Branco C, Palacios S, et al. Tolerability of different oral iron supplements: a systematic review. Curr Med Res Opin 2013;29:291-303.

32. Macdougall IC, Bock AH, Carrera F, et al. FIND-CKD: a randomized trial of intravenous ferric carboxymaltose versus oral iron in patients with chronic kidney disease and iron deficiency anaemia. Nephrol Dial Transplant 2014;29:2075-84.

33. Onken JE, Bregman DB, Harrington RA, et al. A multicenter, randomized, active-controlled study to investigate the efficacy and safety of intravenous ferric carboxymaltose in patients with iron deficiency anemia. Transfusion 2014;54:306-15.

34. Vadhan-Raj S, Strauss W, Ford D, et al. Efficacy and safety of IV ferumoxytol for adults with iron deficiency anemia previously unresponsive to or unable to tolerate oral iron. Am J Hematol 2014;89:7-12.

35. Peters F, Ellermann I, Steinbicker AU. Intravenous Iron for Treatment of Anemia in the 3 Perisurgical Phases: A Review and Analysis of the Current Literature. Anesth Analg 2018;126:1268-82.

36. Froessler B, Palm P, Weber I, et al. The Important Role for Intravenous Iron in Perioperative Patient Blood Management in Major Abdominal Surgery: A Randomized Controlled Trial. Ann Surg 2016;264:41-6.

37. Patient Blood Management National Blood Authority. PREOPERATIVE ANAEMIA IDENTIFICATION, 
ASSESSMENT AND MANAGEMENT - Case study. Guidance for Australian Health Providers [Internet]. www.blood.gov.au. 2014 [cited 2020 Aug 20]. Available online: https://www.blood.gov.au/system/files/documents/ preoperative-anaemia-identification-assessment-andmanagement-case-study\%20grey\%20cover\%20v4.pdf

38. Sim YE, Sim S-ED, Seng C, et al. Preoperative Anemia, Functional Outcomes, and Quality of Life After Hip Fracture Surgery. J Am Geriatr Soc 2018;66:1524-31.

39. Chan DXH, Sim YE, Chan YH, et al. Development of the Combined Assessment of Risk Encountered in Surgery (CARES) surgical risk calculator for prediction of postsurgical mortality and need for intensive care unit admission risk: a single-center retrospective study. BMJ Open 2018;8:e019427.

40. Chiew CJ, Liu N, Wong TH, et al. Utilizing Machine Learning Methods for Preoperative Prediction of Postsurgical Mortality and Intensive Care Unit Admission. Ann Surg 2020;272:1133-9.

41. Ellermann I, Bueckmann A, Eveslage M, et al. Treating Anemia in the Preanesthesia Assessment Clinic: Results of a Retrospective Evaluation. Anesth Analg 2018;127:1202-10

42. Laso-Morales M, Jericó C, Gómez-Ramírez S, et al. Preoperative management of colorectal cancer-induced iron deficiency anemia in clinical practice: data from a large observational cohort. Transfusion 2017;57:3040-8.

43. Calleja JL, Delgado S, del Val A, et al. Ferric carboxymaltose reduces transfusions and hospital stay in patients with colon cancer and anemia. Int J Colorectal Dis 2016;31:543-51.

44. Yoo Y-C, Shim J-K, Kim J-C, et al. Effect of single recombinant human erythropoietin injection on transfusion requirements in preoperatively anemic patients undergoing valvular heart surgery. Anesthesiology 2011;115:929-37.

Cite this article as: Abdullah HR, Thamnachit T, Hao Y, Lim WY, Teo LM, Sim YE. Real-world results of the implementation of preoperative anaemia clinic with intravenous iron therapy for treating iron-deficiency anaemia: a propensitymatched case-control study. Ann Transl Med 2021;9(1):6. doi: 10.21037/atm-20-4942
45. Edwards TJ, Noble EJ, Durran A, et al. Randomized clinical trial of preoperative intravenous iron sucrose to reduce blood transfusion in anaemic patients after colorectal cancer surgery. Br J Surg 2009;96:1122-8.

46. Bernabeu-Wittel M, Romero M, Ollero-Baturone M, et al. Ferric carboxymaltose with or without erythropoietin in anemic patients with hip fracture: a randomized clinical trial. Transfusion 2016;56:2199-211.

47. Frank SM, Savage WJ, Rothschild JA, et al. Variability in blood and blood component utilization as assessed by an anesthesia information management system. Anesthesiology 2012;117:99-106.

48. Bennett-Guerrero E, Zhao Y, O'Brien SM, et al. Variation in use of blood transfusion in coronary artery bypass graft surgery. JAMA 2010;304:1568-75.

49. Rineau E, Chaudet A, Chassier C, et al. Implementing a blood management protocol during the entire perioperative period allows a reduction in transfusion rate in major orthopedic surgery: a before-after .... Transfusion [Internet]. 2016; Available online: https://onlinelibrary. wiley.com/doi/abs/10.1111/trf.13468

50. Khafalafallah A, Al-Barzan AM, Chan J, et al. A Prospective Randomized Controlled Trial to Assess the Effect of Intravenous versus Oral Iron Therapy in the Treatment of Preoperative Anaemia. J Blood Disord Transfusion 2012;3:1-6.

51. Glynn RJ, Schneeweiss S, Stürmer T. Indications for propensity scores and review of their use in pharmacoepidemiology. Basic Clin Pharmacol Toxicol 2006;98:253-9.

52. Ho AMH, Phelan R, Mizubuti GB, et al. Bias in BeforeAfter Studies: Narrative Overview for Anesthesiologists. Anesth Analg 2018;126:1755-62.

53. Implementation research: what it is and how to do it [Internet]. [cited 2019 May 13]. Available online: https:// www.bmj.com/content/347/bmj.f6753.full.print 